\title{
23
}

\section{Characterising Associations between Poverty and Ecosystem Services}

\section{Helen Adams, W. Neil Adger, Sate Ahmad, Ali Ahmed, Dilruba Begum, Mark Chan, Attila N. Lázár, Zoe Matthews, Mohammed Mofizur Rahman, and Peter Kim Streatfield}

\subsection{Introduction}

In order to develop insight and potential actions to co-manage ecosystem services for both healthier ecosystem functioning and to alleviate poverty in natural resource-dependent communities within deltas, it is necessary to understand how poverty is manifest and the level of dependence of populations on the ecosystems and social-ecological systems in which they live and work.

One strategy to develop this insight involves the direct observation of how people live, their own management of the resources around them,

H. Adams $(\bowtie) \bullet$ M. Chan

Department of Geography, King's College London, London, UK

W. Neil Adger

Geography, College of Life and Environmental Sciences, University of Exeter, Exeter, UK

S. Ahmad

Faculty of Agricultural and Environmental Sciences, University of Rostock, Rostock, Germany 
the outcomes of that interaction with ecosystem services in terms of material well-being and their health and their perceptions of those relationships. Hence this research uses social science survey techniques to generate extensive data on the ways in which households use ecosystem services to generate well-being as part of diverse rural livelihoods. In doing so, the survey also provides a quantitative baseline understanding that is also essential to the integrated model (see Chap. 28). Simulations of winners and losers of future interventions on ecosystem services are thus based on real-life starting conditions.

There is significant value in generating primary observational data on ecosystem service use. Alternative sources of social data on life and livelihood include national census data and generalised livelihood surveys, such as the standard Household Income and Expenditure Surveys (HIES) carried out in low-income countries throughout the world (Deaton 1997). Census data are limited to demographic variables, typically with the main occupations of adults within households, and as such give an economic picture of populations. They are less useful to demonstrate where and how people interact with their local environments - the objective of this work (see Chap. 1). Household surveys typically provide detailed analysis of consumption patterns, expenditure patterns and economic activities, as well as demographic

\section{A. Ahmed • D. Begum}

Climate Change and Health, International Center for Diarrheal Disease Research, Bangladesh (icddr,b), Dhaka, Bangladesh

\section{A. N. Lázár}

Faculty of Engineering and the Environment and Tyndall Centre for Climate Change Research, University of Southampton, Southampton, UK

\section{Z. Matthews}

Social Statistics and Demography, Faculty of Social, Human and Mathematical Sciences, University of Southampton, Southampton, UK

M. M. Rahman

International Center for Diarrheal Disease Research, Bangladesh (icddr,b), Dhaka, Bangladesh

P. K. Streatfield

Formerly of the International Center for Diarrheal Disease Research, Bangladesh (icddr,b), Dhaka, Bangladesh 
variables. They do so using nationally representative samples of households from which inferences concerning national trends can be drawn, and the patterns of poverty and well-being are developed. Use of the Bangladesh HIES by Szabo et al. (2016) showed how food security at the household level is negatively associated with creeping salinity in the study area. Yet these data sources are limited in information about the direct benefits people derive from their ecosystems, about their mobility and other responses, and on the health and well-being of populations. Hence the survey here provides a unique set of insights on human-environment relations in this delta.

As highlighted in Chap. 21, ecosystem services are highly variable in space and time. This bespoke survey therefore builds in temporal variability by repeat interviews in three waves over a full calendar year: the analysis constructs detailed livelihood calendars. A further challenge for human-environment models is the multi-dimensional and contested nature of poverty, both as manifest in lack of material assets, an absence of health and also as a lived experience (Baulch 1996). Hence the survey is comprehensive in collecting specific variables that facilitate interdisciplinary analyses and consideration of material and subjective measurements of well-being alongside use of ecosystem services and livelihood diversity. It allows multilevel analysis and intra-household analyses: variables relate to individual men and women and to whole households.

This chapter first briefly outlines the survey methodology and implementation (Sect. 23.2). Section 23.3 summarises the data available from the household survey; it highlights unique variables and aspects of the survey and those that are comparable with other standard datasets. Section 23.4 describes each of the publicly available datasets associated with the household survey, illustrated with selected descriptive statistics. The publicly available datasets are land cover data by Union for the field area in Khulna and Barisal Divisions, household listing data of 9,300 households, a household roster dataset that presents separately the basic data of the 8,000 people living in the households surveyed and three rounds of household survey data for approximately 1,500 separate households taking into account attrition between the three rounds. The chapter closes with a reflection on the reuse potential of the dataset.

All data are available to download from the ReShare UK-based online data repository. ${ }^{1}$ The data are accompanied by English and Bengali versions of the questionnaire, as well as a glossary of terms used in the questionnaire. The survey design process itself is described in more detail in Adams et al. (2016). 


\subsection{Methodology}

This section explains how the survey was carried out. First, it describes the sampling strategy and how the concept of social-ecological systems was operationalised and used to stratify the sample; social-ecological systems were integrated from the beginning. Second, it describes the household listing process, required to ensure a random sampling from within villages. Third, it describes the process of implementing the survey.

\subsubsection{Sampling Strategy}

Households were identified through systematic random sampling. The sample was stratified initially by social-ecological system (SES): rain-fed agriculture, irrigated agriculture, freshwater prawn aquaculture, brackish shrimp aquaculture, coastal aquaculture, riverine areas including eroding islands, and mangrove dependence. These were identified through expert elicitation and land cover maps and verified through semi-structured interviews (see Chap. 22). The sample was not driven by livelihood or ecosystem service use as these changed throughout the year and thus were not compatible with a seasonal approach.

In order to create a sampling frame, a land cover map is overlaid with an administrative map and Unions assigned to a SES. Agricultural and aquaculture systems could be directly assigned based on 80 per cent minimum land coverage per Union. Riverine, marine and Sundarbans systems were assigned based on contiguous boundaries with the associated feature. Some Unions do not have a clearly dominating land use. These Unions were excluded from the sampling process. Table 23.1 shows the number of Unions included in the sampling belonging to each of the strata.

Systematic random sampling was used to select three Unions from each SES and three Mouzas from each Union. A segment of approximately 125 households was listed in each Mouza to randomly select the 21 households that were interviewed. Households were eligible if both a man (aged 18-54) and women (aged 15-49) were present. The target 
Table 23.1 Number of Unions sampled included in each social-ecological system

\begin{tabular}{ll}
\hline Social-ecological system & No. of Unions \\
\hline Rain-fed agriculture & 223 \\
Irrigated agriculture & 29 \\
Freshwater prawn aquaculture & 11 \\
Brackish water shrimp & 31 \\
$\quad$ aquaculture & \\
Charland (riverine) & 17 \\
Sundarban dependent & 24 \\
Coastal periphery & 11 \\
\hline
\end{tabular}

respondent for the survey was the main earner, who completed the structured questionnaire. Information on global satisfaction of life, anthropometry (height and weight) and blood pressure was collected from both a male and a female member of the selected household.

The sample size was calculated based on a head count ratio of poverty prevalence, poverty defined by the inability of households to meet the costs of basic food needs (BBS 2011). In Barisal 27 per cent of people are below this poverty line, and in Khulna 15 per cent and so a population weighted average of 22 per cent was calculated. Ten per cent was added for potentially non-responses, and an additional ten per cent was added to take into account attrition between rounds (although actual attrition rates were below five per cent). Further information on sampling strategy can be found in Adams et al. (2016).

\subsubsection{Survey Implementation}

The survey was administered to selected households three times: first in June 2014, then over October to November 2014 and finally in March 2015 , each time with a four-month recall period. Thus the data covers the period from February 2014 to February 2015. Attrition rates were low: 1,586 households were initially selected; this fell to 1,516 in the second round, and came back up to 1,531 in the third round. However, when all three rounds are considered, 1,478 households have consistent and complete records across the three surveys. 


\subsection{Survey Data}

The survey contains up to nearly 3,000 potential variables corresponding to hundreds of different survey questions contained within 15 different sections. Table 23.2 describes the type of variables that are contained in the survey.

Reuse of the data is facilitated by the interdisciplinary nature of the questions, the number of standard measures of multi-dimensional wellbeing that can be recreated from the data, and the multilevel nature of the data: it can be disaggregated by season, by social-ecological system, by Union, or by individual.

Questions were also included to allow the creation of standard measures to facilitate direct comparison with other surveys. This includes the variables required to recreate the Progress out of Poverty index ${ }^{2}$, the MultiDimensional Poverty Index ${ }^{3}$ and the FANTA III food diversity score. ${ }^{4}$ The survey also contains multiple questions that are also contained within national censuses in order to facilitate comparison and validation.

The items on the asset list (Sect. 2 of the survey) and expenditure (Sects. 13 and 14) were taken from the Bangladesh Household Income and Expenditure 2010 (BBS 2011), with a few additions to take into account the ecosystem service-focus of this research. The global satisfaction with life scale is the same one that is applied in Gallup surveys and

Table 23.2 Metadata summary of the survey data

\begin{tabular}{ll}
\hline Design type & $\begin{array}{c}\text { Systematic random sampled longitudinal household } \\
\text { Factor types }\end{array}$ \\
& $\begin{array}{c}\text { questionnaire survey } \\
\text { and ancome type and livelihood diversification, agricultural } \\
\text { mangrove activities and expenditure, migration, loans, } \\
\text { livestock and poultry, homestead forestry, landholdings, } \\
\text { shocks and migration strategies, place attachment, } \\
\text { perception of environmental quality, household food } \\
\text { diversity, household food consumption, non-food } \\
\text { expenditure, impacts of oil spill, women's empowerment, } \\
\text { height, weight, blood pressure, global satisfaction with life } \\
\text { Bangladesh, social-ecological system, Khulna Division, Barisal } \\
\text { Sample } \\
\text { characterion, household, male aged 18-54, female aged 15-49, } \\
\text { child aged <5 }\end{array}$ \\
\hline
\end{tabular}


the UK well-being survey (Evans 2015; Gallup 2015). The set of nine questions answered on Likert scales to measure place attachment has been previously developed, tested and applied within social psychology and human geography (Lewicka 2011; Devine-Wright 2013).

\subsection{Datasets Available for Reuse}

Each of the datasets described here is openly available for reuse and analysis; some illustrative descriptive statistics are discussed here.

\subsubsection{Land Cover Database}

In addition to the main survey, an Excel spreadsheet is also available ${ }^{5}$ that provides land cover data for each of the Unions in the study area. While this information is used to create a sampling strategy based on SESs, it could also be used to create other land cover-based sampling strategies or to better understand the land use characteristics of Unions in Khulna and Barisal Divisions.

\subsubsection{Household Listing}

A listing was carried out at the start of the data collection process as a rapid census to determine eligibility of households for the full survey. Thus the data comprises a very limited set of variables. However, the value of this dataset lies in the sample size: 9,327 households were surveyed. Data is available for these households on sex and age of the main earner; primary, secondary and tertiary occupation of the earning member; estimated total monthly income in Bangladesh Taka (BDT); and floor, wall and roof materials.

Figure 23.1 shows the average income by social-ecological system disaggregated by sex of the main household earner. Men consistently earn more than women. The coastal periphery SES is worst for income parity, and the freshwater prawn aquaculture zone is the most favourable. However, the difference in average earnings across the systems is twice as great for women than for men. Average income for male household heads varies 
10,000

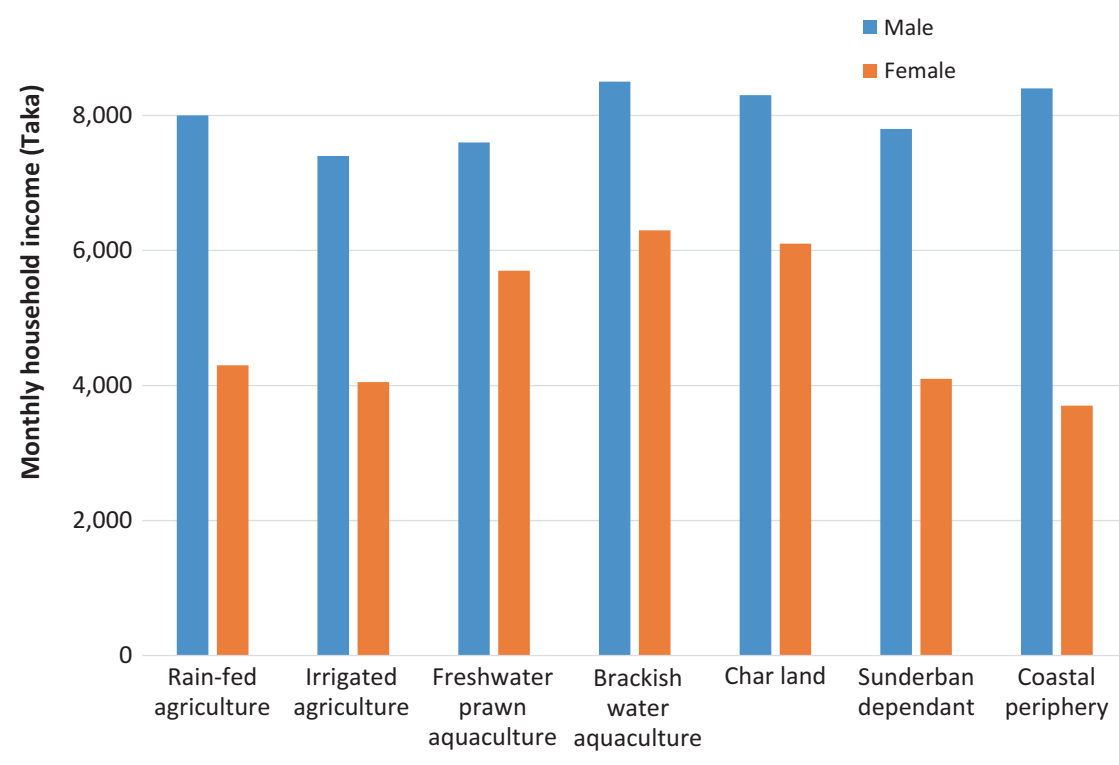

Social-Ecological System

Fig. 23.1 Mean monthly income by social-ecological system and sex from listing data

from 8,508 BDT a month in the riverine system to 7,207 BDT a month in irrigated agricultural SES (a difference of 1,301 BDT). For women, average income varies from 6,447 in the brackish shrimp aquaculture SES to 3,532 in the coastal periphery zone (a difference of 2,915 BDT).

Figure 23.2 shows the most common income sources disaggregated by SES. This includes primary, secondary and tertiary incomes. The five most important income types are shown using two metrics: contribution to total income of the system and the proportion of households involved in this livelihood.

The most common income types vary in ways expected by SES; fishing as an income source is more common in the coastal and riverine zones, pond-based aquaculture is only present in the aquaculture zones (freshwater prawn and brackish shrimp), and agriculture (rain-fed or irrigated) exists across all zones. Interesting findings emerge in the differences between the most common and the most lucrative income types. 


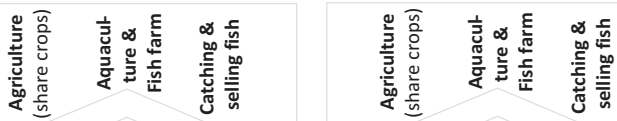
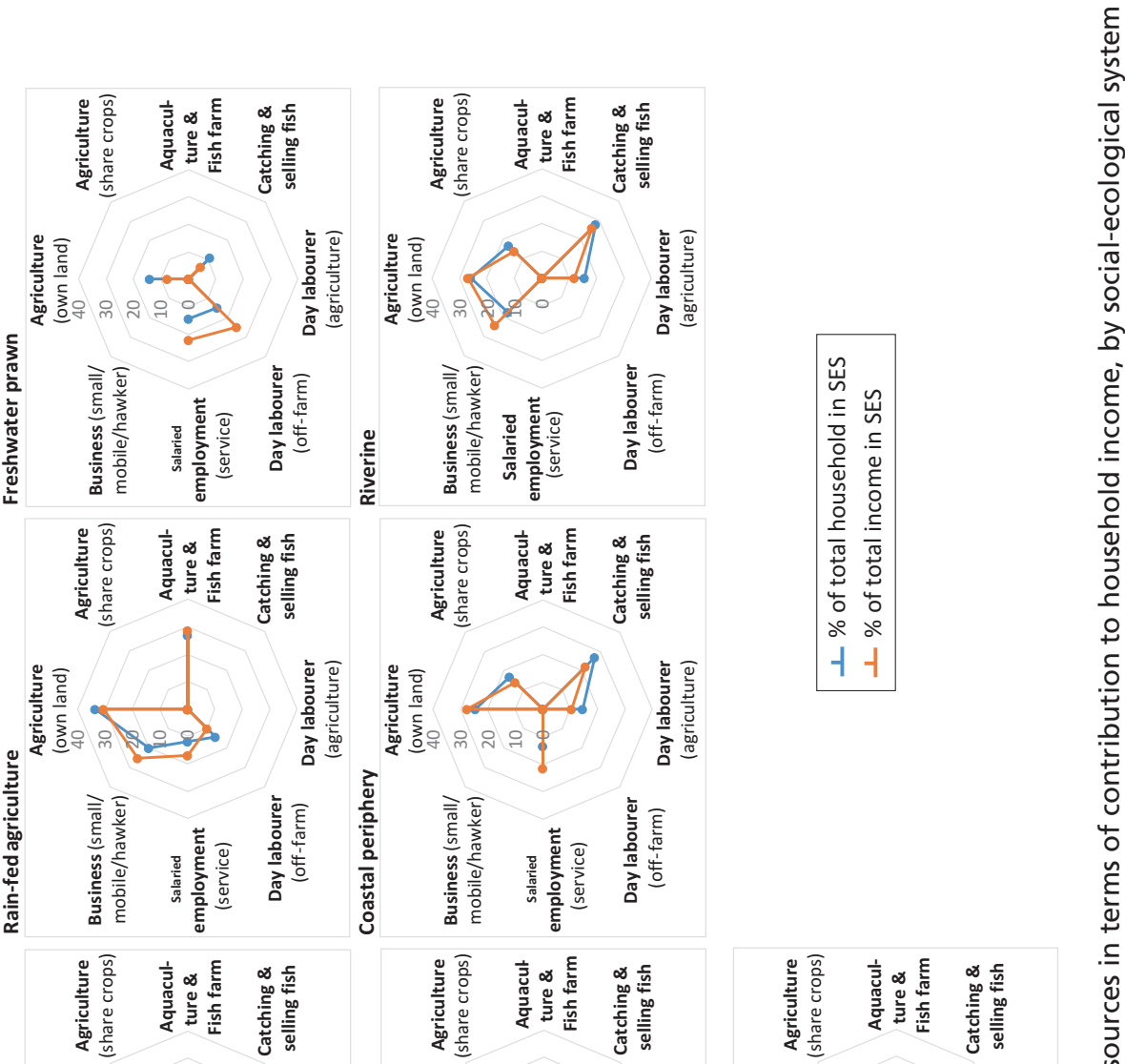

龒

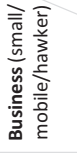

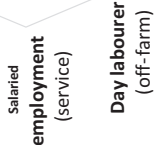

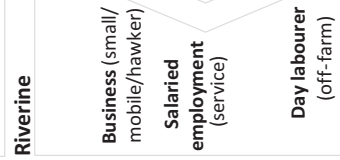

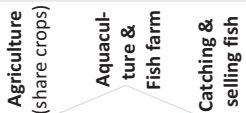



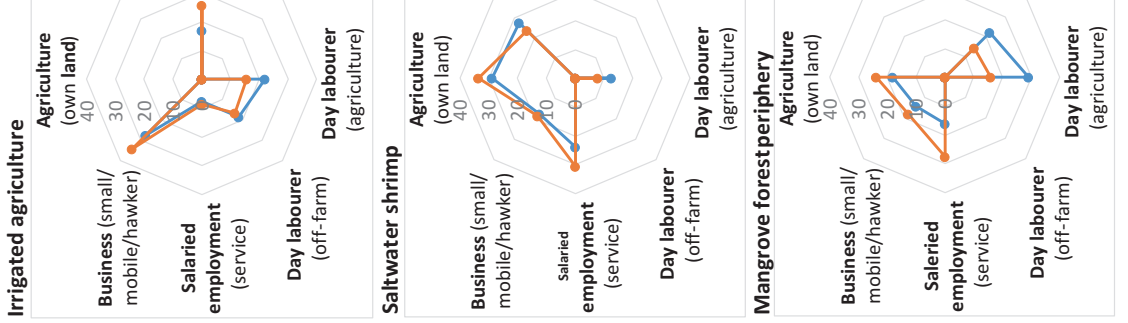

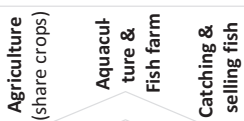

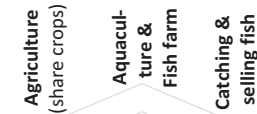


In the Mangrove dependent SES, for example, professional salaried jobs are most important economically, but most households are engaged as day labourers.

\subsubsection{The Household Roster}

The household roster information is available as a separate dataset so the basic characteristics of all individuals included in the survey can be easily analysed. Although the survey was administered to 1,586 households, this comprises 7,993 different women, men and children. Information on whether the person was a visitor or permanent household member, relationship to household head, age, marital status, school attendance, highest level of education reached, number of times the person has attended school, employment status, whether the person is working away and birth place of person (by Upazila and urban/rural) is collected for all three rounds. Figure 23.3 shows the average household size in the survey,

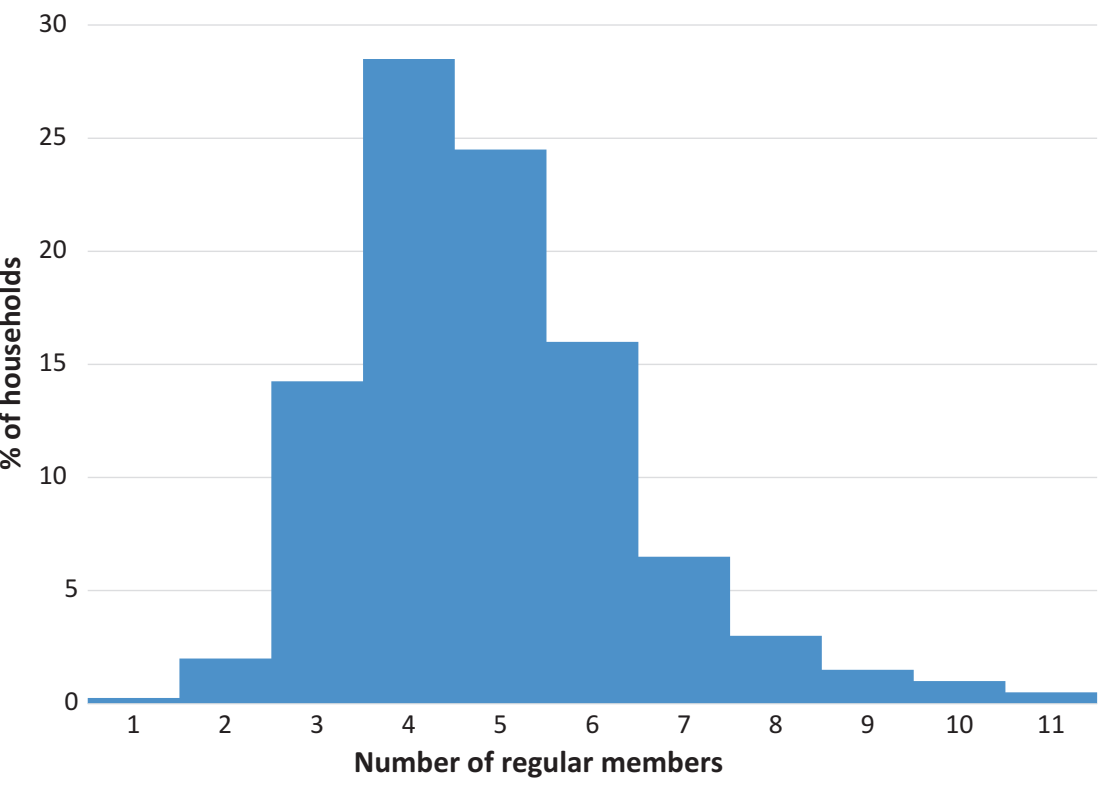

Fig. 23.3 Household size distribution 


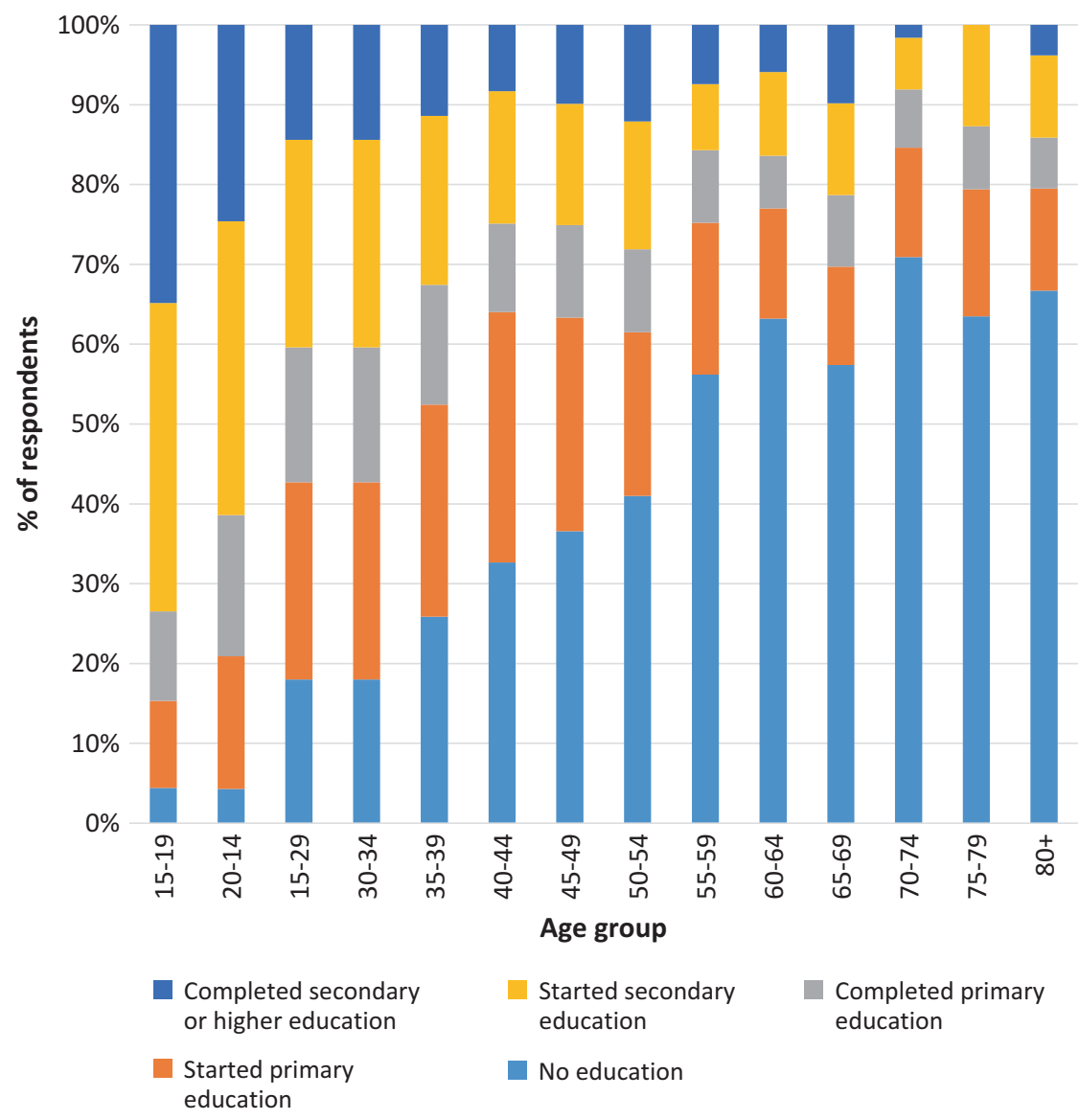

Fig. 23.4 Educational attainment by age group

and Fig. 23.4 shows educational attainment of individuals by age group. Most households had four or five members and educational attainment increases with younger age groups, with people aged 55 and over least likely to have had any education.

Information on place of birth was included in the roster in addition to standard questions on relation to household head, age, education level and income. Analysis of the responses on place of birth show that almost everyone surveyed (90 per cent) was born in the same Upazila in which 
they were now living; therefore this is not an area of in-migration. The approximately ten per cent of the population born outside the Upazila, was made up of women (613 people born outside the Upazila compared to $132 \mathrm{men})$, suggesting that in-migration, where it does occur, is predominantly a result of marriage.

As the household roster was carried out for each round of the survey, a window into changing intra-household dynamics is provided. Table 23.3, for example, shows changes in the percentage of men and women working and the proportion of those working who are migrating outside the village to access these opportunities. A tenth of the number of women are working compared to men. However, in two of the rounds, a very similar proportion of working women as working men were seeking livelihood opportunities outside the village.

\subsubsection{Seasonal Household Survey Variables}

There are three main categories of variable types in the household survey: those with an aim of measuring multi-dimensional poverty, those measuring ecosystem service use and those recording coping strategies used by the household to cope with variability in income.

\subsubsection{Measuring Multi-dimensional Poverty}

Much of the survey instrument is dedicated to the measurement of multidimensional well-being. Various sections of the survey measure material poverty at the household level: Section 2 of the survey records household

Table 23.3 Change in the percentage of men and women working within and outside the village by survey round

\begin{tabular}{lll}
\hline $\begin{array}{l}\text { Round/ } \\
\text { season }\end{array}$ & $\begin{array}{l}\text { Household members working } \\
\text { within the village }\end{array}$ & $\begin{array}{l}\text { Household members working } \\
\text { outside the village }\end{array}$ \\
\hline First & $54 \%$ men & $16 \%$ men \\
& $7 \%$ women & $9 \%$ women \\
Second & $54 \%$ men & $20 \%$ men \\
& $4 \%$ women & $19 \%$ women \\
Third & $54 \%$ men & $18 \%$ men \\
& $4 \%$ women & $19 \%$ women \\
\hline
\end{tabular}


assets, Sect. 3 income type and livelihood diversification, Sect. 9D collects information on landholdings, Sect. 13 on household food diversity and food expenditure and Section 14 non-food expenditure.

Information is also collected to record health status at the individual level. Height, weight and blood pressure of a man, woman and child under five was measured in each household. Chapter 27 focuses on the health outcomes of the survey. Questions on subjective well-being, through a ten-point scale on satisfaction with life, were also asked to men and women separately in each household (Sect. 15 of the survey). Finally, in the third round of the survey, a section was included to measure levels of perceived empowerment of women in the household.

\subsubsection{Ecosystem Use and Quality}

Section 4 of the survey contains four sections on agriculture, aquaculture, fisheries and mangrove activities, including species or variety, productivity, price and profit made. Section 9 contains questions on livestock and poultry and homestead forestry. In addition, questions on perceptions of different dimensions of the quality of the natural environment are asked (Sect. 12). Figures 23.5 and 23.6 provide two examples from this section: on perceptions of water quantity and quality by SES and season. Perceptions change with season and with different SES. While the aquifers from which most water is drawn do not follow the SES boundaries, perceptions of poor water quality are highest where problems of salinity intrusion are most acute. Due to an oil spill occurring in the Sundarbans between the second and third rounds, a module on the impacts of the oil spill was added to the final round.

\subsubsection{Coping Strategies}

The survey instrument contains various sections dedicated to understanding coping strategies. Three sections are dedicated to understanding mobility: past migration and current migration strategies of the household (Sects. 5 and 6 of the survey) and place attachment of the main respondent (Sect. 11). Section 7 is devoted to understanding the use of loans and Sect. 10 examines costs and responses to specific shocks. Table 23.4 shows the source of loans by season. Formal loans from agricultural banks 


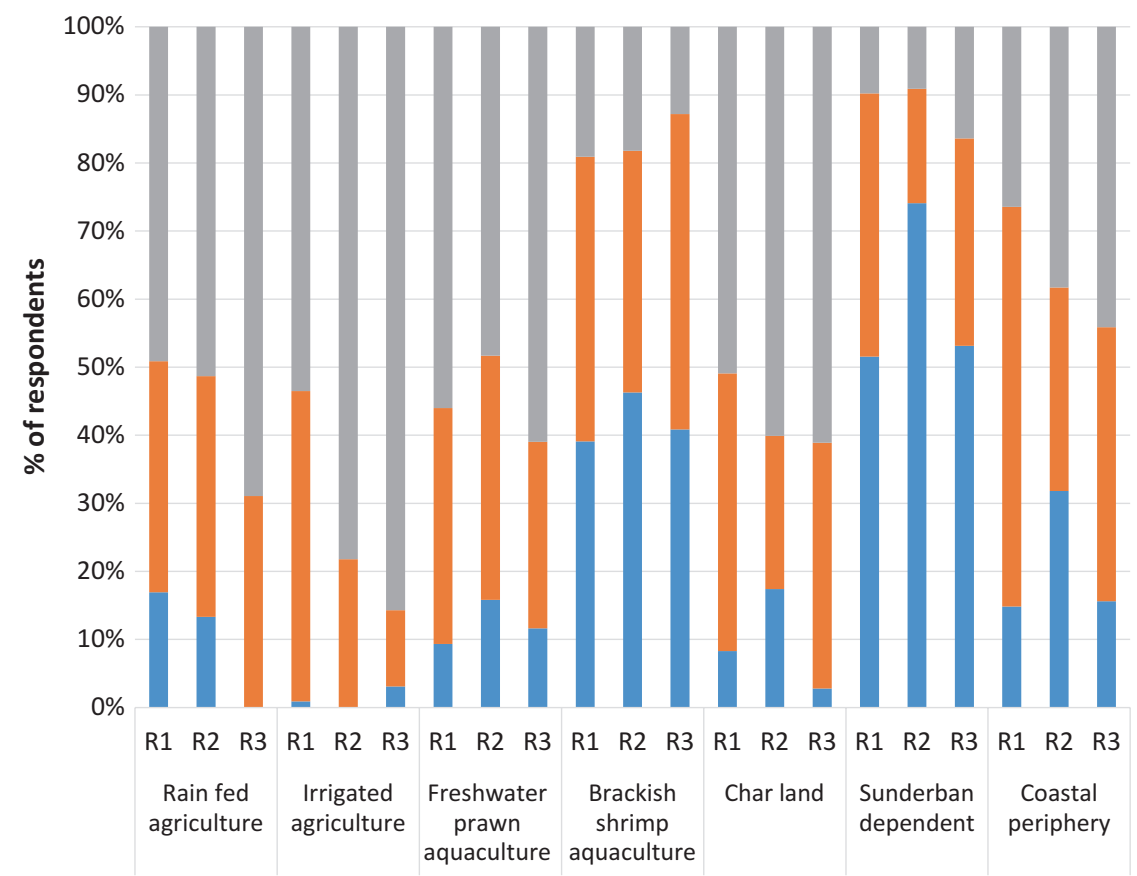

Social-Ecological System

Bad $\quad$ Moderate Good

Fig. 23.5 Respondent perceptions of availability of drinking water by socialecological system throughout the seasons (i.e. rounds-R1-R3)

and non-governmental organisations are most commonly stated as sources of loans, reported approximately five times as often as loans from friends and family are reported. Loans from money lenders are reported slightly less, although people may not want to share the degree to which they owe money in this form.

\subsubsection{Seasonal Changes in Productivity of Ecosystems}

The seasonal nature of the survey and four-month recall period allows for the reconstruction of seasonal calendars for the different ecosystem services. For example, Figs. 23.7 and 23.8 show the total production of 
Characterising Associations between Poverty and Ecosystem...

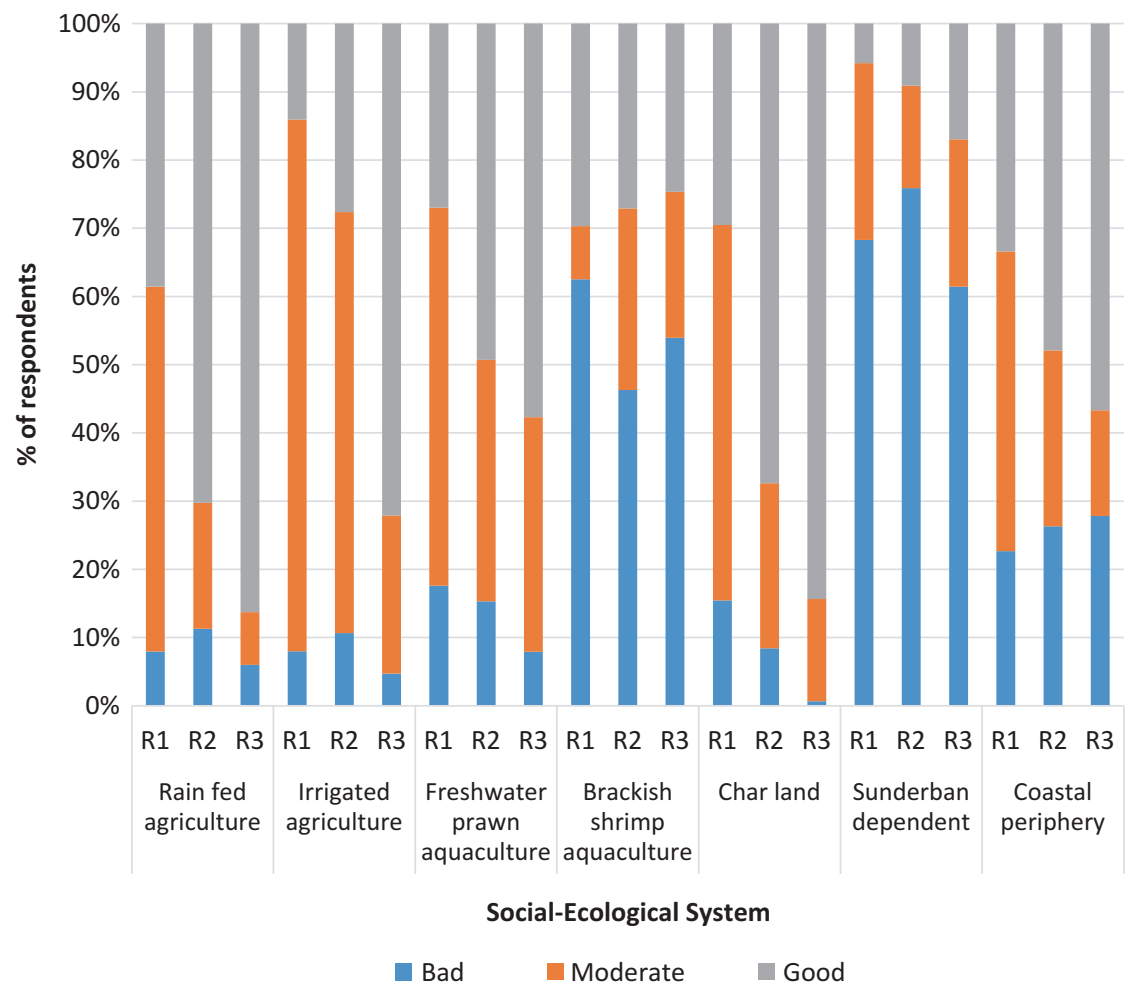

Fig. 23.6 Respondent perceptions of salinity of drinking water by socialecological system in each season (i.e. rounds - R1-R3)

Table 23.4 Number of households taking loans from different sources by survey round

\begin{tabular}{lrcc}
\hline & \multicolumn{3}{l}{ Number of households } \\
\cline { 2 - 4 } Loan type & Round 1 & Round 2 & Round 3 \\
\hline Formal loans only & 305 & 251 & 392 \\
Informal loans only & 42 & 26 & 41 \\
Kinship loans only & 52 & 48 & 66 \\
Loans from patrons & 0 & 0 & 1 \\
Formal and Informal loans & 5 & 4 & 16 \\
Formal and Kinship loans & 7 & 5 & 15 \\
Informal and Kinship loans & 5 & 1 & 5 \\
\hline
\end{tabular}




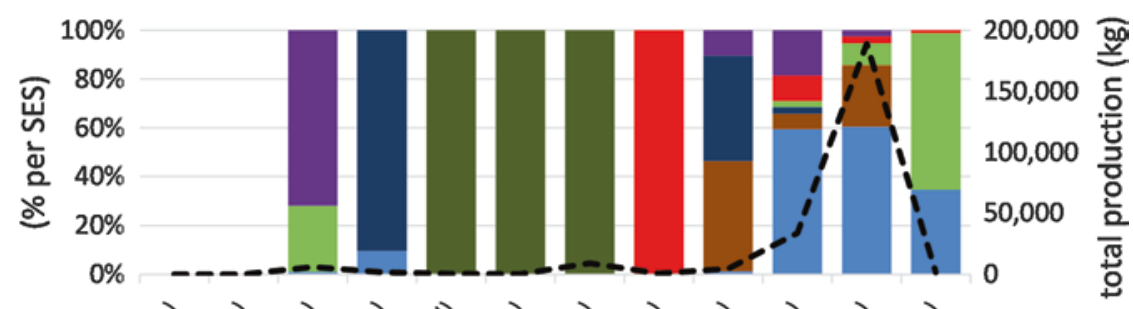

Fig. 23.7 Total Aman rice production in kilograms by social-ecological system and month
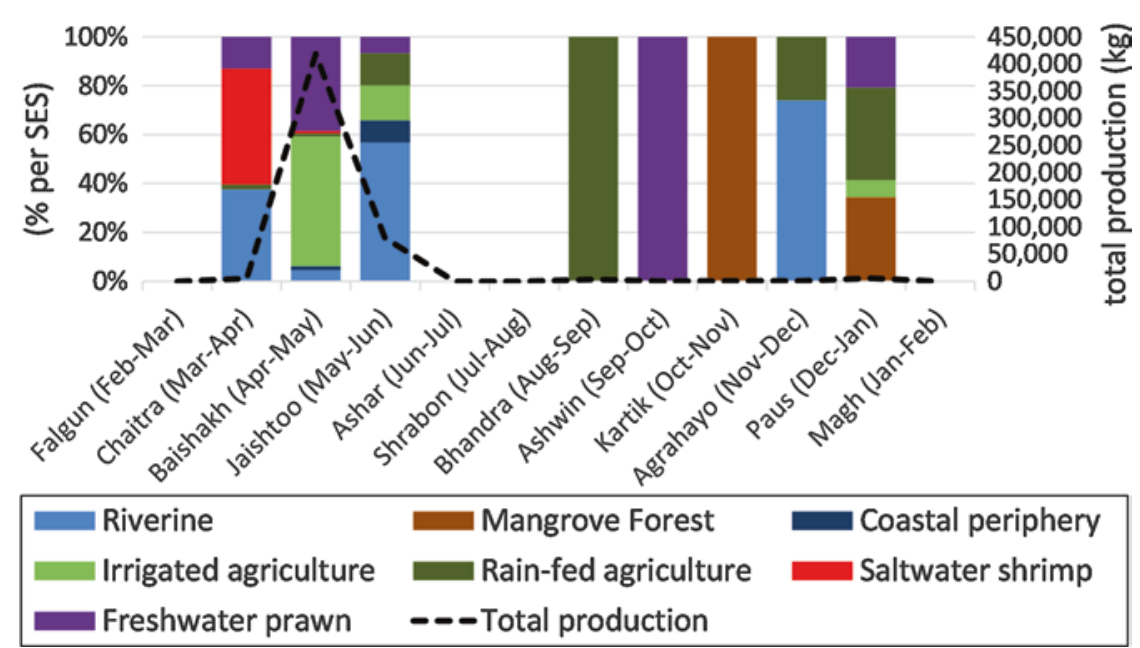

Fig. 23.8 Total Boro rice production in kilograms by social-ecological system and month 
Aman and Boro rice varieties by month for each of the SESs. Aman rice is typically grown during the wet, monsoon season and harvested during the winter; however, it can be grown in small quantities in other months as well. Surprisingly, the Charland SES produces the most Aman rice, followed by the mangrove forest and finally the rain-fed agriculture SES. Boro rice requires irrigation during the dry season and typically harvested during spring. Not surprisingly, the irrigated agriculture SES produces the most Boro rice. Boro rice often produced together with freshwater aquaculture crops, such as fish and prawn. Boro rice is dominantly produced in the irrigated agriculture and freshwater prawn SESs, but the riverine SES also harvests significant quantities of Boro rice.

Figure 23.9 shows seasonality in total fish catch by month for each of the SESs. Fish is generally available all year round. Easy access to the Bay of Bengal fisheries seem to invite fishers in larger quantities: caught fish is most important in the coastal periphery and Charland SESs although during the monsoon months and during the early dry season months (July to January), fishing has some importance in the Sundarban dependent and rain-fed irrigation SESs. Collected data generally refers to Bengali months


Fig. 23.9 Total fish catch in kilograms by social-ecological system and month 
that are slightly offset compared to Western months (e.g. Falgun runs from mid-February to mid-March), figures provides both Bengali and English month names for clarity.

\subsection{Conclusion}

The survey described in this chapter provides key insights into the complexity of rural livelihoods in the coastal zone and helps us to understand the characteristics of households benefitting from ecosystem services and those of households using them as a last resort in the absence of other safety nets. Analysis of the data shows that having any proportion of household income originating in provisioning ecosystem services within farming, aquaculture, fisheries or forest-based livelihoods increases the likelihood of that household being above the poverty line. However, being above a poverty line does not necessarily mean the household is on a positive well-being trajectory, or that they will not fall under the poverty line again. High levels of ecosystem services are associated with high levels of well-being only in those with significant land assets and associated social capital to enter into agriculture-based business opportunities.

The data reported here for the GBM delta demonstrates a wide variety of levels of income and trajectory: while significant proportions of the population would not be classified as being under the poverty line, incomes and the multiple dimensions of well-being are limited throughout the populations surveyed. Further analysis of the survey results shows how these households combine ecosystem services with off-farm livelihoods and risk diversification strategies such as loans and migration, to maintain more secure rural livelihoods.

\section{Notes}

1. Available at https://doi.org/10.5255/UKDA-SN-852179 from the file: Spatial and temporal dynamics of multidimensional well-being, livelihoods and ecosystem services in coastal Bangladesh.

2. http://www.progressoutofpoverty.org/ppi-construction

3. http://www.ophi.org.uk/resources/online-training-portal 
4. http://www.fantaproject.org/research/comparing-household-foodconsumption-indicators-acute-food-insecurity

5. https://doi.org/10.5255/UKDA-SN-852356

\section{References}

Adams, H., W.N. Adger, S. Ahmad, A. Ahmed, D. Begum, A.N. Lázár, Z. Matthews, M.M. Rahman, and P.K. Streatfield. 2016. Spatial and temporal dynamics of multidimensional well-being, livelihoods and ecosystem services in coastal Bangladesh. Scientific Data 3: 160094. https://doi. org/10.1038/sdata.2016.94.

Baulch, B. 1996. Neglected trade-offs in poverty measurement. IDS Bulletin 27 (1): 36-42. https://doi.org/10.1111/j.1759-5436.1996.mp27001004.x.

BBS. 2011[2010]. Report of the household income and expenditure survey. Dhaka: Bangladesh Bureau of Statistics.

Deaton, A. 1997. The analysis of household surveys: a microeconometric approach to development policy. Washington, DC: World Bank and Johns Hopkins University Press. http://documents.worldbank.org/curated/en/593871468777303124/ pdf/multi-page.pdf. Accessed 10 Apr 2017.

Devine-Wright, P. 2013. Explaining NIMBY objections to a power line: The role of personal, place attachment and project-related factors. Environment and Behavior 45 (6): 761-781. https://doi.org/10.1177/0013916512440435.

Evans, J. 2015. Measuring national well-being: Life in the UK, 2015. London: Office for National Statistics. https://www.ons.gov.uk/peoplepopulationandcommunity/wellbeing/articles/measuringnationalwellbeing/2015-03-25. Accessed 10 Apr 2017.

Gallup. 2015. Gallup world poll. www.gallup.com/services/170945/world-poll. aspx. Accessed 17 July 2016.

Lewicka, M. 2011. On the varieties of people's relationships with places: Hummon's typology revisited. Environment and Behavior 43 (5): 676-709. https://doi.org/10.1177/0013916510364917.

Szabo, S., E. Brondizio, F.G. Renaud, S. Hetrick, R.J. Nicholls, Z. Matthews, Z. Tessler, A. Tejedor, Z. Sebesvari, E. Foufoula-Georgiou, S. da Costa, and J.A. Dearing. 2016. Population dynamics, delta vulnerability and environmental change: Comparison of the Mekong, Ganges-Brahmaputra and Amazon delta regions. Sustainability Science 11 (4): 539-554. https:// doi.org/10.1007/s11625-016-0372-6. 
Open Access This chapter is licensed under the terms of the Creative Commons Attribution 4.0 International License (http://creativecommons.org/licenses/ by/4.0/), which permits use, sharing, adaptation, distribution and reproduction in any medium or format, as long as you give appropriate credit to the original author(s) and the source, provide a link to the Creative Commons license and indicate if changes were made.

The images or other third party material in this chapter are included in the chapter's Creative Commons license, unless indicated otherwise in a credit line to the material. If material is not included in the chapter's Creative Commons license and your intended use is not permitted by statutory regulation or exceeds the permitted use, you will need to obtain permission directly from the copyright holder.

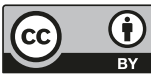

